'Escola Superior de Ciências da Santa Casa de Misericórdia de Vitória (Emescam) - Vitória (ES), Brasil.

kallendw@gmail.com

2 Universidade Federal do Espírito Santo (Ufes) Vitória (ES), Brasil.

\section{A normatização de condutas realizadas pelas Comunidades Terapêuticas}

\author{
The standardization of conducts carried out by the Therapeutic \\ Communities
}

Klindia Ramos Barcelos', Kallen Dettmann Wandekoken², Maristela Dalbello-Araujo', Bruna Ceruti Quintanilha²

DOI: $10.1590 / 0103-1104202112810$

RESUMO Neste artigo, foram analisadas as consequências subjetivas decorrentes da internação em uma rede de Comunidades Terapêuticas (CT) a partir das vozes dos egressos. Trata-se de uma pesquisa de abordagem qualitativa, por meio de entrevistas semiestruturadas com dez sujeitos. Os resultados são apresentados esmiuçando a terapêutica realizada nas CT. Os participantes a descreveram como baseada em privação de liberdade, dos meios de comunicação e do convívio social, ficando patente que o objetivo é promover o total isolamento e produzir a normatização de condutas. A rede pesquisada configura-se como instituição total por ser idealizada para oferecer internação aos usuários de drogas, entendidos como sujeitos impossibilitados de cuidar de si e que apresentam elevado grau de perigo para todos que estão a sua volta, razão pela qual precisam ser enclausurados e apartados do seu convívio social. Essas instituições ancoram-se em quatro pilares: disciplina, trabalho, convivência e, especialmente, abordagem religiosa, a fim de promover a anulação das subjetividades pregressas, suas singularidades e desejos em prol de uma nova subjetividade - aquela engessada segundo as prerrogativas que vicejam nesses espaços, o que as torna semelhantes aos confinamentos predominantes nos antigos manicômios.

PALAVRAS-CHAVE Política pública. Comunidade terapêutica. Saúde mental.

ABSTRACT In this article we analyze the subjective consequences resulting from hospitalization in a network of Therapeutic Communities (TC), based on the voices of the graduates. It is a qualitative research, through semi-structured interviews with ten subjects. The results are presented by examining the therapy carried out in the TC. The participants described it as based on deprivation of freedom, the media and social life, making it clear that the objective is to promote total isolation and produce the standardization of conducts. The researched network is configured as a total institution because it was idealized to offer hospitalization to drug users, who are seen as subjects unable to take care of themselves and who present a high degree of danger to everyone around them, which is why they need to be cloistered and severed from their social coexistence. Those institutions are anchored on four pillars: discipline, work, coexistence and, especially, on the religious approach, in order to promote the annulment of past subjectivities, their singularities and desires in favor of a new subjectivity - one that is immobilized in accordance with the prerogatives that thrive in those spaces, which makes them similar to the predominant confinements in the old asylums.

KEYWORDS Public policy. Therapeutic community. Mental health. 


\section{Introdução}

A partir de 1990, verifica-se um aumento considerável na procura por tratamento para aqueles que fazem uso abusivo de Substâncias Psicoativas (SP) e a expansão do número de Comunidades Terapêuticas (CT) no Brasil1. Essas instituições surgiram em razão do espaço deixado pelas políticas públicas em relação à problemática, visto que somente em 2003 foi promulgada pelo Ministério da Saúde uma política específica ${ }^{2,3}$.

Tais comunidades foram regulamentadas pela Resolução no 29 , de junho de 2011, da Agência Nacional de Vigilância Sanitária (Anvisa); e em dezembro de 2011, a Portaria $\mathrm{n}^{\mathrm{0}} 3.088 / 2011$ as incluiu como um dos serviços da Rede de Atenção Psicossocial (Raps), o que implica financiamento por parte do Sistema Único de Saúde (SUS) 4,5. Elas oferecem um tratamento residencial fechado, fundamentado na concepção de que é preciso mudar a condição, o contexto e realizar a retirada da pessoa do ambiente em que o consumo ocorre, pois se torna necessário que sua personalidade seja transformada para haver a reinserção social. Concordam que a transformação deve ser incentivada por meio de um tratamento com intervenções pessoais e sociais, nas quais se aplicam atribuições e responsabilidades aos internos, entendendo que eles se encontram em um contexto livre das drogas e, por isso, propício para o desenvolvimento de novos valores, como solidariedade, honestidade, responsabilidade, amor e espiritualidade ${ }^{6}$.

Ribeiro e Minayo ${ }^{7}$ afirmam que o ideário das CT brasileiras pressupõe que a recuperação e a reabilitação dos usuários só podem ocorrer por meio da evangelização e da conversão religiosa. Além disso, embora cada uma possua suas especificidades, existem algumas diretrizes básicas que lhes são comuns: são constituídas por um sistema bem estruturado que define horários e regras que delimitam, de forma rigorosa, as responsabilidades de cada interno; são construídas, majoritariamente, na zona rural; fundamentadas em normas restritas e na disciplina - dentre as quais, pode-se destacar: o distanciamento dos internos de seu local de origem, a laborterapia, o trabalho em grupo e a abstinência total do uso de drogas como requisito para permanência no serviço.

Cabe assinalar que essa modalidade de serviço vem recebendo diversas críticas, denúncias e fiscalizações rigorosas, como a realizada pelo Conselho Federal de Psicologia (CFP), que culminou na publicação do 'Relatório da 4 a inspeção nacional de direitos humanos: locais de internação para usuários de drogas'. Este documento apontou práticas dissonantes do que preconizam o movimento da reforma psiquiátrica e a luta antimanicomial no Brasil. Dentre elas, sobressaem a falta de respeito à cidadania dos usuários e os métodos que desvelaram indícios de violação de direitos humanos 5,8. O Conselho Federal de Serviço Social (CFESS) também se posicionou contra a regulamentação de tais locais enquanto serviços de saúde por entender que esse tratamento deve ficar a cargo do SUS - em consonância com o que foi deliberado na IV Conferência de Saúde Mental em 2010, na XIV Conferência Nacional de Saúde em 2011 e, sobretudo, na Lei $n^{0} 10.216 / 2001^{9}$. Além destes, destacam-se: o 'Relatório da inspeção nacional em CTs' que constatou privação de liberdade; as claras características asilares e de segregação; a violação de direitos; o rompimento de laços sociais e o emprego de uma abordagem que não privilegia a singularidade do sujeito, uma vez que não dispõe de um projeto terapêutico para cada indivíduo, conforme exigido pela Portaria $\mathrm{n}^{0} 3.088 / 2011^{10}$.

$\mathrm{Na}$ esteira das reprovações a esses serviços, Ribeiro e Minayo ${ }^{7}$ tecem críticas sobre o enfoque utilizado por essas instituições: a manutenção do distanciamento do sujeito da comunidade, o que leva ao rompimento com os vínculos sociais, comunitários, empregatícios, educacionais e de saúde; o processo de recuperação que não contempla o confronto do indivíduo com o uso de drogas, visto que oferece a ideia de um 'contexto seguro' e distante do meio em que o consumo se dá; a 
exploração do trabalho, encoberta pelo discurso da laborterapia como recurso terapêutico; a ênfase demasiadamente religiosa; e, ainda, as diversas dissonâncias entre o delimitado pelas políticas públicas e o praticado por tais comunidades. Nesse contexto, Pitta ${ }^{11}$ assevera de que tal modelo de serviço apenas enclausura o problema, diante da inexistência de uma intervenção mais efetiva e eficaz por parte do Estado. Além destes, o estudo de Leal, Santos e Jesus ${ }^{\mathbf{1 2}}$ revelou que, no estado do Espírito Santo, a solução ofertada às pessoas que fazem uso de vários tipos de substâncias tem sido o isolamento em instituições privadas, clínicas ou CT, revelando uma marcante dissonância com o que é preconizado pela reforma psiquiátrica.

Em face do exposto, fica clara a premência por pesquisas que almejem conhecer o que ocorre nesses serviços e suas repercussões para a vida dos internos. Assim, neste artigo, discutem-se as consequências subjetivas decorrentes da internação em uma rede de CT a partir dos olhares e das vozes dos egressos.

\section{Material e métodos}

Trata-se de uma pesquisa de abordagem qualitativa, considerando a perspectiva do egresso desses estabelecimentos como elemento de análise. Para coleta dos dados, foram realizadas entrevistas individuais com roteiro semiestruturado, visando explorar em profundidade as vivências dos indivíduos ${ }^{\mathbf{1 3}}$. Foram entrevistados 10 homens, maiores de 18 anos, todos egressos da maior rede de comunidades do País ${ }^{14}$. Esta pesquisa foi submetida à Plataforma Brasil, ficando registrada sob o número 86616218.4.0000.5065 com parecer $\mathrm{n}^{0} 2.618 .473$, recebendo posterior aprovação do Comitê de Ética em Pesquisa da Escola Superior de Ciências da Santa Casa de Misericórdia de Vitória - CEP/Emescam.

Todas as entrevistas foram gravadas, transcritas na íntegra e submetidas à técnica de análise de conteúdo proposta por Bardin ${ }^{15}$, que compreende três fases: pré-análise; exploração do material e tratamento dos resultados. Visando anonimato, os extratos de falas foram identificados pela letra ' $\mathrm{E}$ '.

\section{Resultados e discussão}

Com o propósito de enfatizar a análise crítica, os resultados são agrupados na categoria terapêutica realizada; e, para facilitar o entendimento de suas dimensões, subdividida em: as privações vivenciadas, a disciplina, a espiritualidade e o trabalho.

\section{A terapêutica}

Ao serem inqueridos sobre o 'tratamento' dispensado nessas instituições, os participantes frisaram que a internação visava 'algo além', pois nesses locais, o objetivo não é cuidar das pessoas que fazem uso das SP, mas reeducá-las, o que implica uma mudança de vida, hábitos e sentimentos. Como mostra o relato, o participante parece concordar com o que é efetivado pela CT:

O intuito da comunidade não é curar de drogas.

O que ela te oferece, o que ela quer para você é uma vida nova. [...] lá você vai precisar viver uma vida nova. Uma mudança de vida, de hábitos, de costumes. (E5).

Natalino ${ }^{16}$ aponta que a finalidade última desse tipo de instituição é incutir no usuário uma nova identidade, produzindo novos sujeitos que correspondam ao modelo moral preestabelecido por esses serviços, ou seja, indivíduos disciplinados, produtivos e tementes a Deus. Para tanto, o caminho para essa nova vida é o mesmo para todos os internos: renunciar ao mundo externo, renunciar à vida pregressa em sua totalidade e adotar as ideologias que ali são preconizadas. Espera-se com isso administrar a reinvenção do eu do interno, o que restringe o seu leque de possibilidades de reconstrução de vínculos com a sociedade e fortalece a dependência ao universo moral e disciplinar fomentado por esses serviços. 
Santos ${ }^{17}$ menciona que a proposta da reeducação é sustentada pela percepção que esses serviços possuem acerca do interno. Nessas instituições, eles são concebidos como indivíduos sem controle de seus impulsos, incapazes de postergar suas satisfações e que visualizam a realidade de forma disfuncional. Logo, são reconhecidos como doentes e moralmente fracos, ao passo que a dependência química é vista como persistente e incurável. O pensamento corrente nesses serviços é de que o estilo de vida dos internos não é condizente com os códigos de normas morais e sociais que regem a vida em sociedade. Além disso, entendem que aquele que faz uso de SP gera conflitos familiares, torna-se manipulador, irresponsável, alienado de suas razões e vontades e torna-se criminoso, pois se envolverá em roubos. Por isso a necessidade de reeducá-lo e reformá-lo moralmente, com intuito de retornar para a sociedade com uma nova identidade que foi forjada pelo código moral que a orienta. Evidenciado no trecho:

[...] lá [na CT] você vai precisar viver uma vida nova. Uma mudança de vida, de hábitos, de costumes, de acabar com o seu egoísmo, sua arrogância, sua prepotência, que são drogas muito maiores do que as drogas de cocaína. É uma reeducação, isso é vida nova, é mudança de hábito, de costume, pegar na mão igual criança e começar tudo de novo. É assim que tem que ser. (E5).

Nota-se que os usuários são tomados de forma descolada do contexto social e que atribuem ao uso de SP uma conotação de pecado ou de doença incurável, ou seja, como um problema peculiar ao sujeito e que, por isso, só poderá ser vencido por ele ${ }^{18}$. Cabe, então, questionar: que subjetividades são produzidas por essa reeducação?

Assis, Barreiros e Conceição ${ }^{19}$ garantem que quando é proposto um tratamento no qual há necessidade de isolar a pessoa da sociedade com o intuito de moldá-la, a partir de um modo padronizado de existência, o que na verdade acontece é a anulação dos desejos do sujeito, por meio do bloqueio do processo de construção de subjetividades livres e autônomas. Nesse sentido, apontam ${ }^{20}$ que, em tais instituições, a subjetividade de cada interno não é reconhecida e valorizada, posto que todos devem adaptar-se às verdades que ali são preestabelecidas.

Além disso, elas utilizam uma abordagem culpabilizante ao tratar o uso de SP sob a ótica da abstinência, desconsiderando os aspectos históricos, sociais, políticos e econômicos inerentes a essa problemática. Tais ideias são ainda mais evidentes na subcategoria descrita a seguir.

\section{As privações vivenciadas}

Predomina a percepção de que as comunidades se constituem em espaço de privação de liberdade, dos meios de comunicação e do convívio social, até mesmo dos familiares. Fica patente que o objetivo é promover a total segregação e isolamento do mundo externo, e não apenas a ruptura dos pacientes com a substância que os levou a ingressarem no serviço.

Os sujeitos evidenciam que as privações vivenciadas durante o processo de internação se aproximam das que ocorrem nas prisões, uma realidade chocante para aqueles que são internados. As vivências de confinamento foram apontadas como geradoras do sentimento de saudade da família e, também, anunciadas como experiências que resultam em estresse emocional e psicológico. Isso pode ser constado nos relatos:

Eu nunca estive internado e, de repente, você se ver preso, fora de casa. Não é uma cadeia, mas você fica privado de várias coisas. Televisão e rádio você não tem, celular não pode usar, sua família fica longe. (E3).

Na comunidade [terapêutica] a gente tem que ficar três meses sem ver a nossa família. E ficar esses três meses longe da família é um choque. O tratamento todo é um choque. É uma realidade que choca qualquer um. É um choque você se ver privado de tudo. (E5). 
Essa situação de confinamento me deixou estressado psicologicamente e emocionalmente, cheguei ao meu limite e quando completei seis meses, saí. E também eu sentia saudades da minha família, porque ficamos afastados de familiares, porque só pode ter visita quando completa três meses, e aí a nossa família vai uma vez por mês só. (E7).

Os depoimentos são preocupantes e remontam àquilo que ocorria nos manicômios. Há quem defenda as comunidades, alegando que tal comparação não procede, uma vez que a internação na CT é voluntária. Porém, é preciso dizer que, muitas vezes, ela é feita de maneira compulsória com a ajuda da justiça, que, acionada pela família, frequentemente, defere pedidos de internação nesses estabelecimentos.

O tipo de abordagem preconiza que o sujeito só estará apto a retornar à sociedade após pelo menos 12 meses de internação. Os relatos obtidos por meio das entrevistas deixam explícito que são locais de privação de liberdade, fechados e que reeditam o sistema de isolamento, segregação, sequestração e confinamento, predominante nos antigos manicômios e leprosários.

Tais características foram constatadas também em vários estudos $5,10,21-24$ que apontaram frequentes práticas que violam o direito de ir e vir do usuário, além de proibirem o uso dos meios de comunicação, o que distancia os internos de seus familiares.

No que concerne à comparação dessas instituições com o modelo manicomial, Fossi e Guareschi22 assinalam que as privações de liberdade vivenciadas pelos internos são análogas à ideia de tratamento em saúde mental, no qual, aos indivíduos ditos como loucos, restava a exclusão social, a imposição de regras de conduta e o encarceramento em espaços isolados da sociedade.

O isolamento do louco se dava sob a justificativa da periculosidade que ele representava. Atualmente, fundamentam suas práticas na premissa de que a pessoa que faz uso abusivo de SP gera risco para a sociedade e sua família, pois porta uma doença sobre a qual não possui controle dos instintos, o que a torna perigosa e incontrolável, logo, deve ser confinada. Tal imagem tem sido reforçada pela mídia, o que aumenta o discurso social favorável a internação ${ }^{25}$.

As atuais comunidades, assim como os antigos manicômios, podem ser compreendidas como 'instituições totais', visto que possuem caráter fechado e total, expresso por meio das privações e restrições do mundo externo $^{26}$. Goffman ${ }^{26}$ ainda afirma que uma instituição total é um espaço de residência e trabalho, construído para afastar do convívio social indivíduos que vivem situações semelhantes de marginalidade, levando-os a viver uma vida formalmente administrada e fechada, marcada pela rotina diária, juntamente com um grupo de pessoas que trazem consigo o mesmo status institucional, que, no caso de nossa pesquisa, é o status de uso abusivo de substância psicoativa. Ressalta que as instituições totais podem ser vistas como estufas para mudar pessoas; para isso, lançam mão de estratégias que rebaixam, degradam, desmoralizam, profanam e mortificam o 'eu' do interno, de forma a padronizar uma nova identidade no sujeito.

Nesse sentido, a rede de CT pesquisada é configurada como instituição total por ser idealizada para oferecer tratamento que visa alocar os usuários em locais afastados do convívio social, com obrigatoriedade de realização de atividades diárias e adesão de preceitos religiosos, sob a justificativa de que apresentam elevado grau de periculosidade.

Os internos relatam danos irreparáveis devido ao período em que ficam internados: prejuízos na carreira profissional, no desenvolvimento educacional, no relacionamento amoroso e na criação dos filhos. Alguns papéis legais também podem ser avariados como consequência da barreira que os distanciou do mundo externo, como a perda temporária dos direitos de dispor de dinheiro, de se manifestar em oposição a um processo de adoção ou divórcio, de exercer a sua cidadania por meio 
do voto. Por isso, é comum entre os internos a prevalência do sentimento de que o período confinado foi um tempo suprimido, sobretudo em virtude das perdas sociais resultantes do processo de internação.

Os sujeitos deste estudo demonstraram ter sofrido prejuízos no âmbito afetivo e material, manifestando que, após a internação, foram tomados pelo desejo de ter de volta tudo o que foi perdido em função do processo de internação; como pode ser comprovado no relato:

Quando você tem alta, muitas vezes, você quer aquilo tudo de volta. Eu perdi um relacionamento de oito anos e uma casa, que deixei para trás quando fui internado. Não foi fácil não. Sonhos, planos, eu tive que 'matar' um sonho de ser pai por causa da internação. E às vezes eu me frustro muito, sabe? Muitas das vezes eu olho para trás e vejo que se talvez eu não tivesse me afastado, talvez eu tivesse as minhas coisas ainda. (E3).

\section{A disciplina}

Constatou-se que a disciplina nesses locais opera por meio da imposição de normas e regras bem rígidas, bem como por meio da punição que poderá incidir sobre o interno, caso este venha a descumprir as regras e normas. Os internos são coagidos a cumprir com todas as regras e horários e são levados a orientar a sua vida diária a partir do que é ditado pela direção. Enfatiza-se que a disciplina imposta se torna tão enraizada e naturalizada pelos internos que as punições e as obrigações não são vistas como tais.

Na comunidade tem as normas de lá, se você não seguir as normas direito, você é... Eles te eliminam, né? Para você não ficar lá. Só que não tem nada obrigatório que você tem que fazer, não. Você tem uma função lá, por exemplo, minha função era trabalhar na horta. Mas, se eu não fizesse, eu poderia ser mandado embora. (E4).
[...] Eu questionava, por que eu não posso isso? Por que não posso passar da cerca? Por que não posso ir à outra casa? Eu era muito questionador, tudo queria saber por que, para quê. Queria entender o processo para aceitar a recuperação. Aí isso gerava atrito com os coordenadores, porque eles pensavam: 'o cara questiona demais', aí eles me deixavam uma semana na horta, para eu parar de questionar, isso me estressava um pouco. A gente não podia ultrapassar esses limites da fazenda, tinha regras, tinha que obedecer. (E7).

A disciplina que se mostra arraigada nos dispositivos de internação visa obter o controle contínuo e absoluto sobre os sujeitos por meio de recursos disciplinares bem precisos, tais como: controle de posturas, de atividades e tempo, entendidos como imprescindíveis para adestrar esses indivíduos, em que a punição se revela como imperioso instrumento para repressão, a fim de que os internos se sujeitem à disciplina imposta27.

Os entrevistados compreendem que são sujeitos que possuem aversão a regras e normas e que, por isso, precisam delas para a sua reeducação. Nesse sentido, Goffman ${ }^{26}$ chama a atenção de que é comum nas instituições totais o interno sofrer com o que ele denomina 'lavagem de cérebro'. Isso corresponde ao processo de aceitação do modelo de conduta preconizado pelos seus dirigentes como o melhor para o interno.

Também há privilégios para quem é obediente no cumprimento das regras impostas. Nas CT estudadas, essas vantagens consistem no acesso ao esporte e à leitura de livros. Em contrapartida, como consequência da desobediência, os internos são submetidos a castigos, como a retirada temporária ou permanente dos benefícios. Tanto os castigos quanto os privilégios são entendidos como peculiares às instituições totais. Nestas, não há espaço para as escolhas pessoais, pois elas precisam ser anuladas em face das obrigações específicas. Assim, escolhas simples, como a hora de levantar pela manhã e horário para almoçar, tornam-se problemáticas ${ }^{26}$. 
Por último, faz-se também oportuno recorrer à reflexão sugerida por Foucault ${ }^{\mathbf{2 8}}$ sobre dispositivos de controle. Para esse teórico, a disciplina visa à fabricação de corpos dóceis, ou seja, corpos submissos, exercitados, de fácil adestramento, que possam ser produtivos e úteis. Desse modo, pode-se dizer que a disciplina proposta nesses serviços tem em vista a produção de corpos dóceis e adestrados para se submeterem ao ideal de tratamento proposto, a fim de serem transformados segundo as prerrogativas moralizantes e normatizantes que operam nesses espaços. Questão esta que, de fato, "limita as possibilidades de resgate da concepção de sujeito e subjetividade no processo de produção do cuidado às pessoas em sofrimento psíquico”29(178).

\section{O trabalho}

Denominado como laborterapia, o trabalho representa $92,90 \%$ dos recursos empregados pelas CT brasileiras ${ }^{30}$. Tal preponderância deve-se ao pressuposto de que ele é capaz de gerar autodisciplina e autocontrole, vistos como fundamentais para garantir o sucesso na vida social após a internação.

A concepção do trabalho como recurso terapêutico data do século XVIII, sob influência da teoria do tratamento moral desenvolvida por Pinel. Nele, o trabalho exerce função corretiva, disciplinadora e alienante, empregado como meio para a organização e manutenção do contexto asilar, ao mesmo tempo que se contrapõe à ociosidade. Esse recurso era visto como terapêutico por, supostamente, ser capaz de devolver ao sujeito a racionalidade perdida, reorganizar seus comportamentos e restabelecer costumes saudáveis ${ }^{31}$.

Naquele contexto, a valorização do trabalho se coadunava com os anseios da nova sociedade capitalista, que rejeita a ociosidade e supervaloriza a produtividade. Tal panorama somente foi modificado pela substituição do modelo de tratamento asilar por uma rede de atenção psicossocial de base territorial, na qual o trabalho passou a ser utilizado como instrumento para reinserção social dos pacientes assistidos pela política de saúde mental ${ }^{\mathbf{3 1}}$.

Nesse ponto, os achados desta pesquisa expressam que tais instituições retomam a concepção do trabalho predominante no século XVIII. Estão evidentes nos discursos dos egressos, uma vez que estes parecem se submeter ao ideal de tratamento proposto, como corpos dóceis:

Lá trabalha muito, são oito horas por dia. Mas, eu gosto do trabalho, essa é a parte boa, aprendi a tirar leite, fazer pão, biscoitos, bolo, artesanato, terço, comida para 20,30 pessoas. Até os meninos brincam, eu já brinquei também: 'olha onde eu vim parar' com a enxada na mão naquele sol quente. 'Está vendo, foi usar droga, olha onde você vem parar'. (E10).

Bolonheis-Ramos e Boarini ${ }^{23}$ enfatizam que muitas são as críticas a esse recurso de tratamento largamente utilizado pelas comunidades. Tais críticas estão sustentadas, especialmente, no entendimento de que a finalidade última do trabalho nesses locais consiste apenas na manutenção do funcionamento da própria CT, não abarcando, portanto, qualquer finalidade terapêutica capaz de contribuir para a reinserção social do interno.

Para Melo ${ }^{32}$, o trabalho proposto nesses estabelecimentos não é capaz de oferecer instrumentos de cidadania ou autonomia. Ao contrário disso, desempenha uma função moral disciplinadora, que visa aprisionar e normatizar os internos, segundo os padrões exigidos por essas instituições; e, assim, limitar suas diversas possibilidades de vida, mortificar suas trajetórias e peculiaridades, incutindo-lhes uma nova identidade que traduz as premissas desses espaços.

Considerando que o exercício do trabalho nos estabelecimentos estudados constitui-se em mais uma das tantas tarefas obrigatórias, é necessário questionar se, de fato, esse recurso, da forma como é empregado, pode ser capaz de desenvolver a autoestima e a criatividade do interno. Indaga-se ainda se esse recurso 
traz consigo qualquer finalidade terapêutica, no sentido de trazer contribuições para a posterior reinserção social do interno.

$\mathrm{Na}$ esteira desses questionamentos, os resultados da inspeção realizada pelo CFP ${ }^{10}$ sustentam que as atividades desenvolvidas pelos internos nesses espaços não possuem nenhum objetivo terapêutico. Longe disso, constituem forma de exploração, visando aumentar os lucros do serviço ao substituir a contratação de profissionais pela utilização da mão de obra dos internos que trabalham de forma gratuita e, geralmente, forçados, em condições precárias e sem nenhuma garantia trabalhista. Nesses espaços, o trabalho é utilizado como instrumento de disciplina e punição, não privilegia a expressão individual e não contribui para o processo de reinserção do interno, pois não facilita o desenvolvimento de potencialidade ou de qualificação profissional.

\section{Religiosidade}

Na concepção dos entrevistados, o pilar espiritualidade se materializa por meio da prática da reza do terço, da leitura e vivência da palavra do dia e da participação nas missas. Para esses sujeitos, a vivência dessas práticas é fonte de força para a suposta cura e configura-se enquanto meio para que possam aceitar as regras, anular suas vontades e corrigir comportamentos inadequados.

A espiritualidade é muito alta lá, muito grande, fortalece muito a gente. Tem os padres, pessoas que estão ali para ajudar a gente. Isso oferece para gente uma vida nova de entender que as coisas não são como eu quero, e que eu preciso aceitar as coisas para ter uma vida nova. Ah, por que não tem televisão? Por que não tem rádio? Por que essa luz é assim? É um tanto de 'por que', não tem mais por que, 'morre' a sua vontade, faz o que tem que ser feito. É para acordar 7 horas da manhã, é para dormir 14 horas da tarde. Aceita, é só isso. As coisas não são do jeito que eu quero, como eu quero. Então essa mudança que a fazenda faz na gente, é aceitar as coisas. (E5).
Dados publicados pelo Instituto de Pesquisa Econômica Aplicada (Ipea) ${ }^{30}$ mostram que a espiritualidade representa 95,6\% dos métodos empregados pelas CT brasileiras. Todavia, a espiritualidade incentivada por esses serviços está, geralmente, atrelada a confissões religiosas utilizadas como meio para promover a fé dos usuários em um ser ou instância superior, visando transformar suas vidas; objetivando enquadrá-los moralmente; amenizar suas dores e sofrimentos e auxiliar na superação do uso de SP. Assim, pôde-se perceber que o termo espiritualidade constante nos panfletos de propaganda da instituição se refere a um eufemismo, visto que por espiritualidade se entende e se pratica uma determinada ordem religiosa, imposta como a correta e única.

Valendo-se do sistema de crenças oriundo do catolicismo, os serviços analisados buscam moldar os internos segundo os preceitos dessa religião, para que um 'novo homem nasça' e o ‘velho homem' seja exterminado, ou seja, é preciso que a personalidade pregressa seja anulada para dar vazão a uma nova personalidade, consonante com os modos de vida desejados por essas instituições.

A gente aprende que existe um homem velho e o homem novo. O homem velho não pode nascer, eu tenho que deixar o homem novo nascer todos os dias. (E5).

Morria muito da minha vontade, na fazenda ensina você morrer do seu próprio eu, morrer de si. Tipo assim, a pessoa fez uma coisa que você não gostou e você tem que aprender a ficar na sua, 'morrer' do próprio eu, se você não falar daquilo, você vai ficar tranquilo, não vai fazer nada e deixar, fazer a vontade de Deus. (E10).

Essa constatação se revela consonante com o estudo de Fossi e Guareschi ${ }^{22}$ que indicam que os rituais religiosos, comuns em grande parte desse tipo de serviço, são utilizados como meio para levar o indivíduo à abnegação de suas próprias vontades. Também Medeiros ${ }^{33}$ aponta que, nesses locais, o uso de drogas é 
tido como doença, maldição, castigo e um mal 'espiritual' provocado pela interrupção abrupta do sujeito com os códigos socialmente aceitos. A partir desse entendimento, o caminho para cura consiste na conversão religiosa, pois só assim os internos se tornarão aptos a obedecer às ordens que lhes são impostas. Entretanto, essa cura só é possível quando o interno reconhece o próprio desvio ou desobediência e, assim, reflete e se arrepende de seus atos desviantes e pecaminosos. Além disso, os rituais religiosos são utilizados por essas instituições como meio para levar o sujeito a uma condição de fragilidade emocional, vulnerabilidade e humilhação, entendidas como condição indispensável para educar e normatizar os internos - isso porque, nesse contexto, o interno se reconhece como incapaz de cuidar de si e, por efeito, entrega o governo de sua vida aos coordenadores desses serviços. Vale ressaltar que, nas CT estudadas, esses coordenadores, geralmente, são residentes que estão no último mês de internação, trabalham de forma voluntária para manter a rotina destas e não precisam ter formação técnica e/ ou acadêmica para ocupar o cargo.

\section{Considerações finais}

Ao se analisar as consequências subjetivas decorrentes da internação em uma rede de $\mathrm{CT}$, verifica-se que ela se constitui meio para normatizar seus internos. Para tanto, ancora-se em quatro pilares: disciplina, trabalho, convivência e, especialmente, abordagem religiosa, a fim de promover a anulação da subjetividade pregressa dos internos, em prol de uma nova subjetividade: aquela forjada segundo as prerrogativas que operam nesses espaços.

A disciplina nesses serviços é explicitada por meio da imposição de normas e regras que administram o tempo dos residentes, a partir de uma rotina padronizada e da adesão aos preceitos religiosos que ali são professados. Além disso, a punição revela-se como o principal artifício para produzir pessoas humildes, adestradas e obedientes às normas e regras impostas.

Constata-se que a abordagem religiosa empregada é moralizante, disciplinadora, culpabilizante e violadora de direitos. Moralizante por ter como proposta a revisão moral do estilo de vida do sujeito. Disciplinadora, já que utiliza de rituais religiosos como meio para tornar seus residentes humildes para obedecer e aceitar as ordens que lhe são dadas. Culpabilizante por considerar a causa do uso de drogas como problema individual do sujeito, desconsiderando, assim, os aspectos históricos, econômicos, sociais e políticos que perpassam esse uso e fazendo recair sobre o indivíduo a inteira responsabilidade por sua recuperação. Violadora de direitos, posto que a participação nas práticas religiosas, rotinas de horários e trabalho é obrigatória, mesmo que o indivíduo não partilhe do que ali é prescrito.

Essas questões fazem problematizar a eficácia das CT, de forma que se torna imprescindível a avaliação e o monitoramento por parte do Estado. Outrossim, para além disso, faz-se necessário o devido investimento em dispositivos territoriais, com foco nos Centros de Atenção Psicossocial Álcool e Drogas, a fim de propiciar uma abordagem que busque a autonomia do usuário, com propostas individualizadas e que valorizam as diferentes subjetividades.

\section{Colaboradoras}

Barcelos KR (0000-0001-6959-1759)*, Wandekoken KD (0000-0002-2326-4880)*, Dalbello-Araujo M (0000-0002-9950-3358)* e Quintanilha BC (0000-0002-2826-7183)* contribuíram igualmente para a elaboração do manuscrito. 


\section{Referências}

1. Alves VS. Modelos de atenção à saúde de usuários de álcool e outras drogas: discursos políticos, saberes e práticas. Cad. Saúde Pública. 2009; 23(11):2309-2319.

2. Costa SF. As políticas públicas e as comunidades terapêuticas nos atendimentos à dependência química. Serv. Soc. Rev. 2009; 3(2):1-14.

3. Brasil. Ministério da Saúde, Coordenação Nacional de DST e AIDS. Política do Ministério da Saúde para atenção integral a usuários de álcool e outras drogas. Brasília, DF: MS; 2003.

4. Brasil. Ministério da Saúde. Resolução da Diretoria Colegiada $n^{\circ} 29$, de 30 de junho de 2011. Dispõe sobre os requisitos de segurança sanitária para o funcionamento de instituições que prestem serviços de atenção a pessoas com transtornos decorrentes do uso, abuso ou dependência de substâncias psicoativas. Diário Oficial da União. 30 Jun 2011.

5. Brasil. Ministério da Saúde. Portaria no 3.088, de 23 de dezembro de 2011. Institui a Rede de Atenção Psicossocial para pessoas com sofrimento ou transtorno mental e com necessidades decorrentes do uso de crack, álcool e outras drogas, no âmbito do Sistema Único de Saúde. Diário Oficial da União. 23 Dez 2011.

6. Sabino NM, Cazanave SOS. Comunidades terapêuticas como forma de tratamento para a dependência de substâncias psicoativas. Estud. Psicol. 2005; 22(2):167-174.

7. Ribeiro FML, Minayo MCS. As Comunidades Terapêuticas religiosas na recuperação de dependentes de drogas: o caso de Manguinhos, RJ, Brasil. Interface (Botucatu). 2015: 19(54):515-526.

8. Conselho Federal de Psicologia. Relatório da $4^{\mathrm{a}}$ Inspeção Nacional de Direitos Humanos: locais de internação para usuários de drogas. 2. ed. Brasília, DF: Conselho Federal de Psicologia; 2011.

9. Conselho Federal de Serviço Social. Nota sobre a regulamentação das comunidades terapêuticas: contri- buições do CFESS para o debate. Brasília, DF: CFSN; 2014.

10. Conselho Federal de Psicologia. CFP repudia mudanças na política de saúde mental. Brasília, DF: CFP; 2017.

11. Pitta AMF. Um balanço da reforma psiquiátrica brasileira: instituições, atores e políticas. Ciênc. Saúde Colet. 2011; 16(12):4579-4589.

12. Leal FX, Santos CCM, Jesus RS. Política Sobre Drogas no Estado do Espírito Santo: consolidando retrocessos. Text. \& Cont. 2016; 15(2):423-436.

13. Gaskell G. Entrevistas individuais e grupais. In: Bauer MW, Gaskell G, editores. Pesquisa qualitativa com texto: imagem e som: um manual prático. Petrópolis: Vozes; 2002.

14. Galindo D, Moura M, Pimentel-Mello R. Comunidades terapêuticas para pessoas que fazem uso de drogas: uma política de confinamento. Barbarói. 2017; (50):226-247.

15. Bardin L. Análise de conteúdo. São Paulo: Edições $70 ; 2011$.

16. Natalino MAC. Isolamento, disciplina e destino social em comunidades terapêuticas. In: Santos MPG, organizador. Comunidades terapêuticas: temas para reflexão. Rio de Janeiro: IPEA; 2018. p. 37-60.

17. Santos MPG. Comunidades terapêuticas e a disputa sobre modelos de atenção a usuários de drogas no Brasil. In: Santos MPG, organizador. Comunidades terapêuticas: temas para reflexão. Rio de Janeiro: IPEA; 2018. p. 17-36.

18. Loeck JF. Comunidades terapêuticas e a transformação moral dos indivíduos: entre o religioso-espiritual e o técnico-científico. In: Santos MPG, organizador. Comunidades terapêuticas: temas para reflexão, Rio de Janeiro: IPEA; 2018. p. 77-100. 
19. Assis JT, Barreiros GB, Conceição MIG. A internação para usuários de drogas: diálogos com a reforma psiquiátrica. Rev. Latino Am. Psicopatol. Fundam. 2013; 16(4):584-596.

20. Raupp LM, Sapiro CM. A “reeducação” de adolescentes em uma comunidade terapêutica: o tratamento da drogadição em uma instituição religiosa. Psic.: Teor. e Pesq. 2008; 24(3):361-368.

21. Pacheco AL, Scisleski A. Vivências em uma comunidade terapêutica. Rev. Psicol. Saúde. 2013; 5(2):165173.

22. Fossi LB, Guareschi NMF. O modelo de tratamento das comunidades terapêuticas: práticas confessionais na conformação dos sujeitos. Estud. Pesqui. 23. Bolonheis-Ramos RCM, Boarini ML. Comunidades terapêuticas: "novas" perspectivas e propostas higienistas. História, Ciências, Saúde-manguinhos. 2015; 22(4):1231-1248.

23. Bolonheis-Ramos RCM, Boarini ML. Comunidades terapêuticas: "novas" perspectivas e propostas higienistas. História, Ciências, Saúde-manguinhos. 2015; 22(4):1231-1248.

24. Ferrazza DA, Sanches RR, Justo JS. Comunidades Terapêuticas em novas configurações do manicomialismo. ECOS. Estud. Contemp. Subj. 2017; 2(7):363-375.

25. Andrade TM. Reflexões sobre políticas de drogas no Brasil. Ciênc. Saúde Colet. 2011; 16(12):4665-4674.

26. Goffman E. Manicômios, prisões e conventos. São Paulo: Perspectiva; 1987.
27. Amarante P. Entrevista: Paulo Amarante fala sobre a proposta de reformulação da Política Nacional de Saúde Mental. Rio de Janeiro: Laps; ENSP; Fiocruz; 2017.

28. Foucault M. Microfísica do Poder. 29. ed. Rio de Janeiro: Edições Graal; 2011.

29. Barbosa VFB, Martinhago F, Hoepfner AMS, et al. O cuidado em saúde mental no Brasil: uma leitura a partir dos dispositivos de biopoder e biopolítica. Saúde debate. 2016: 40(108):178-189.

30. Instituto de Pesquisa Econômica Aplicada. Nota técnica perfil das comunidades terapêuticas brasileiras. $\mathrm{n}^{\circ}$ 21, Diretoria de Estudos e Políticas do Estado, das Instituições e da Democracia. Brasília, DF: IPEA; 2017.

31. Shimoguiri AFDT, Costa-Rosa A. Do tratamento moral à atenção psicossocial: a terapia ocupacional a partir da reforma psiquiátrica brasileira. Interface (Botucatu). 2017: 21(63):845-856.

32. Melo JRF, Maciel SC. Representação Social do Usuário de Drogas na Perspectiva de Dependentes Químicos. Psicologia: Ciênc. Prof. 2016; 36(1):76-87.

33. Medeiros R. Construção social das drogas e do crack e as respostas institucionais e terapêuticas instituídas. Saúde Soc. 2014; 23(1):105-117.

Recebido em 13/02/2020

Aprovado em 25/09/2020 Conflito de interesses: inexistente

Suporte financeiro: não houve 